http://dx.doi.org/10.12795/PH.1991.v06.i01.22

\title{
Introducción a una poética bajitiniana de Ernesto Sábato
}

Carmen Espejo Cala

\section{Realismo grotesco y carnavalización}

...«Qué ansiedad tiene la gente de ese carnaval por el absoluto, qué insaciable sed» ${ }^{1}$. El universo de Sábato, como bien conocen sus críticos y lectores, evidencia el desconsuelo del mísero ser humano, desgarrado entre sus ansias de trascendencia y su sujeción irremisible a una materia rápidamente corruptible.

La actitud del autor y sus personajes ante este condicionamiento existencial no es melancólica o resignada, sino agónica y violenta, y así sus novelas recrean una humanidad paroxística atrapada en un macabro carnaval que los conduce en un soplo de la nada a la vida, al dolor y el amor, y de allí a la muerte y otra vez a la nada.

Sus obras son, por tanto, productos desorbitados, desmesurados, desde el dato físico de la extensión (en torno a las quinientas páginas en sus dos últimas novelas, Sobre héroes y tumbas y Abaddón el exterminador), hasta elementos esenciales como el tono discursivo o la estructura narrativa.

No resultaría desatinada la referencia a François Rabelais, aunque nos interesa más ahora atender a la interpretación que de la literatura rabelesiana ha dado Mijail Bajtin en su ensayo La cultura popular en la Edad Media y Renacimiento. Bajtin parte, en efecto, del análisis de la obra fundamental de Rabelais, Dostoievski o Cervantes para completar todo un modelo original de crítica textual en la que basaremos nuestra revisión de las dos últimas novelas de Sábato. De antemano podemos anunciar que, si bien no descubriremos prácticamente recurso o técnica alguna en la obra del argentino, podremos sin embargo intentar la comprensión de todas aquellos elementos sabatianos ya señalados por la crítica dentro de un universo coherente en su deformación sistemática y de larga ascendencia literaria.

Pero volvamos a Rabelais. Bajtin encuadra al genio francés en lo que llama cultura popular, manifestación sociocultural que, enraizada en la civilización primitiva como

${ }^{1}$ Emesto Sábato, Abaddón el exterminador (Barcelona: Seix Barral, 1984), p. 94. 
parte insoslayable del desenvolvimiento humano, llega a la civilización medieval y renacentista a través de griegos y romanos. Esta cultura popular se desarrolla en múltiples manifestaciones, desde fórmulas del espectáculo como el carnaval a la elaboración literaria de la parodia o los diferentes modos del vocabulario familiar y grosero. Supone en cualquier caso la irrupción de una risa ritual que reedita irreverentemente los discursos serios de la sociedad, y convierte a los héroes en objeto de mofa.

De este modo, el carnaval -fórmula en la que Bajtin incluye desde las saturnales romanas a las danzas de la muerte medievales- ofrece una visión del mundo deliberadamente degradada, donde se explicita una concepción dual de la existencia en la que cada cual es otro por unos días, las relaciones -sociales, sexuales. . .- se liberalizan, y las fronteras de los tabúes son abolidas transitoriamente. Es, explica Bajtin, un segundo modo, una segunda vida, el acceso al reino utópico de la libertad y la igualdad.

Toda esta insólita vida pletórica del pueblo impregna la gran literatura y, para acercarnos ya a nuestro objetivo, deja impronta en maestros renacentistas como Rabelais o Cervantes, para desde allí alcanzar a los contemporáneos: Sábato entre ellos. Es esta lectura la que puede explicar el fondo cómico del «Informe sobre ciegos» de Sobre héroes y tumbas, donde Fernando Vidal Olmos considera hallarse, mientras lee los graffitti satíricos o groseros de un excusado público, ante el «reverso del mundo» ${ }^{2}$, y se siente, poco más adelante, «una especie de héroe, de héroe al revés, héroe negro y repugnante, pero héroe. Una especie de Sigfrido de las tinieblas...» ${ }^{3}$. ¿No es acaso un contrafactum paródico la teodicea delirante del doctor Alberto J. Gandulfo, que en Abaddón el exterminador diserta sobre el poder de Satanás en la tierra, a través de una impostura que nos obliga a confundirlo con Cristo?

Otros motivos tópicos del carnaval como los monstruos (los que pueblan los subsuelos fantasmagóricos de ambas novelas) y las metamorfosis zoomórficas (hombres-murciélago, hombres-lagarto, hombres-serpiente, hombres-águila, etc.) son elementos recurrentes en ambas novelas. Pero un análisis más sistematizado nos lleva al concepto bajtiniano del realismo grotesco, nombre con el que el crítico ruso denomina a la herencia literaria de la cultura popular hasta aquí evocada.

Lo que define al realismo grotesco es la utilización del universo corporal, material, sexual, biológico, alimenticio, pero ante todo su utilización positiva. Emplea un procedimiento de degradación de todo lo espiritual y abstracto que acerca al individuo a su origen: el vientre, los órganos genitales, desde donde se expulsa lo putrefacto pero también lo regenerador, la nueva vida. Si las religiones occidentales prometen la salvación del alma mediante la negación del cuerpo, la cultura popular y su reflejo en el realismo grotesco aseguran la regeneración de la vida terrena a través de, a partir del cuerpo.

¿Por qué, entonces, ese ideal inveterado de todos los personajes de Sábato, que solicitan hasta el asesinato o el suicidio una concepción espiritual de la existencia en

\footnotetext{
${ }^{2}$ Emesto Sábato, Sobre héroes y tumbas, (Barcelona: Seix Barral, 1987), p. 356.

${ }^{3}$ Sobre héroes, p. 425.
} 
general y del amor y el sexo en particular? El mismo Bajtin aporta una via para la explicación cuando analiza el devenir histórico del realismo grotesco: el romanticismo lo mutiló, eliminando el carácter regenerador de la risa carnavalesca e incidiendo en los caracteres tenebrosos de lo grotesco. El mundo material se observa entonces como repugnante, nocturno, terrorífico, y el simpático diablo de los apólogos medievales se transforma en la fuerza incontrastable del Mal todopoderoso.

Este es, sin duda, el grotesco de Ernesto Sábato, que tiñe todos los episodios de sus novelas y se hace explícito en secuencias como la de Alejandra y Marcos Molina, descrito «con esa teatralidad que tenemos cuando adolescentes... grotesco y conmovedor» ${ }^{4}$. La misma aventura subterránea de Fernando Vidal Olmos adquiere un aire de macabro humorismo, cuando Bruno la relaciona con «perrerías tragicómicas» de un ente diabólico:

Curioso: la palabra tragicómico es la primera vez que acude a mi mente con respecto a la personalidad de Fernando, pero creo que también responde a la verdad. Fernando fue una persona fundamentalmente trágica, pero hay momentos de su existencia que bordean el humor, bien que se trate de un humor tenebroso ${ }^{5}$.

En Abaddón el exterminador el realismo grotesco alcanza igualmente a definir todos los personajes fundamentales de la trama: Nacho y Agustina son descritos, en su primera aparición, con recursos deformantes cercanos a lo esperpéntico:

Eran hermanos, sin ninguna clase de duda. Y él tendría un año o dos menos que ella. Su expresión le habra resultado sarcástica, y sus manos, muy huesudas y largas, se contráan con una fuerza desproporcionada: había algo inarmónico en todo él, sus movimientos eran abruptos, repentinos y torpes ${ }^{6}$.

Schneider, príncipe de las tinieblas sabatianas, es un acabado muestrario de los rasgos aplicados por Bajtin al grotesco romántico:

Schneider, era grotesco pero sombrí, ruidoso pero tenebrosamente secreto. Sus carcajadas ocultaban un espíritu sigiloso, como una caricaturesca y risible máscara un semblante duro, esquemático y reservado rostro del infierno. Como alguien que mientras prepara un calculado y frígido crimen cuenta chistes verdes a su futura víctima ${ }^{7}$.

De este modo, inserto en una tradición de tenebrismo tragicómico que Bajtin hace provenirdel Romanticismo, en Sobre héroes y tumbas el novelista argentino ha exorcizado sus fantasmas personales a través de un escalofriante aquelarre que constituye su régimen de lo nocturno: hablamos del ambiente de «pesadilla tenebrosa» en que Martín

${ }^{4}$ Sobre héroes, p. 80.

${ }^{5}$ Sobre héroes, p. 471.

${ }^{6}$ Abaddón, p. 58.

${ }^{7}$ Abaddón, p. 40. 
se ve envuelto desde las primeras páginas de la novela, de la alucinación febril de Fernando que lo hace ingresar en el infiemo subterráneo, del «oscuro laberinto» que ha precedido a la redacción del texto según confesión del propio Sábato en la nota preliminar, y, por no extendernos más en aspectos tan conocidos, del universo de los versos con que se abre el «Informe sobre ciegos»:

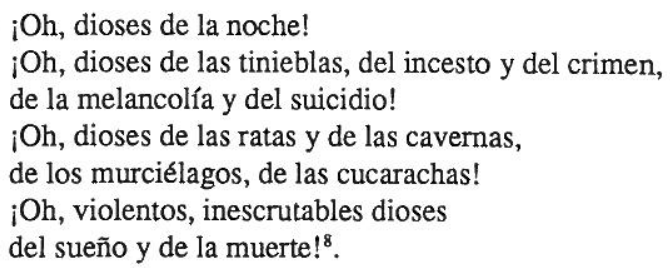

Sin la contundencia que alcanza en Sobre héroes y tumbas, Abaddón el exterminador reproduce igualmente el cosmos negro de la pesadilla y lo diabólico: así, el sótano en que Sábato cumple su extraño rito erótico con Soledad, el planeta sin sol descrito en las páginas finales o la clarividencia con la que el narrador Sábato, recordando los episodios de su vida parisina, explica que «sin saberlo, estaba virando yo de la parte iluminada de la existencia a la parte oscura»?.

El concepto de realismo grotesco en la reinterpretación que de él hace el Romanticismo explica por tanto la atmósfera nocturnal de sus novelas. En otro campo, este legado cultural recubre de sentido la mayoría de los procedimientos narrativos de Sábato. Alberto Julián Pérez, que ha analizado desde supuestos bajtinianos la cuentística de Jorge Luis Borges, sistematiza los efectos técnicos del realismo grotesco en éstos que enumeramos sintéticamente -y es significativo hallar juntos a Borges y Sábato a través de un enfoque renovador como éste-:

a) la ambigüedad y la ambivalencia (pares serio-cómicos, transformaciones y metamorfosis, dobles...);

b) la elevación y el rebajamiento (inversiones, hipérboles);

c) la comicidad y la ironía(parodias, etc.);

d) la deformación.

En mayor o menor medida, todos estos recursos son evidentes en la narrativa sabatiana. En Sobre héroes y tumbas los personajes son representados a través de la angustiosa dualidad que lastra o potencia el perfeccionamiento humano. Así, en las primeras páginas, Martín es descrito físicamente por las frases de Alejandra como un proyecto de asceta español en el que revientan unos labios sensuales y contradictorios. Alejandra es una mujer sin un solo rasgo de la dulzura que caracteriza al sexo femenino, observa luego Martín, una excitante mezcla de inocencia y corrupción, «como si una chica que todavía juega con las muñecas fuera al mismo tiempo capaz de espantosas

${ }^{8}$ Sobre héroes, p. 287.

${ }^{9}$ Abaddón, p. 306. 
sabidurías de viejo» ${ }^{10}$. La duplicidad del personaje femenino consigue su máxima expresión al final del capítulo «El dragón y la princesa»:

Y lo más extraño de todo era que él quería a ese monstruo equívoco: dragónprincesa, rosafango, niñamurciélago. A ese mismo casto, caliente y acaso corrupto ser que se estremecía cerca de él, agitado quién sabe por qué horrendas pesadillas ${ }^{11}$.

Tal como los personajes, las experiencias vividas o las nociones abstractas son paradójicas y equívocas. En la concepción de Sábato, hay risas que se descubren como anómala manifestación del llanto, desamparados anónimos frente a los impostores del desamparo, episodios históricos sujetos a interpretaciones contradictorias y, en general, dos fuerzas opuestas -el Bien y el Mal- que organizan nuestra existencia en dolorosos compartimentos estancos que el amor y el arte tratan inútilmente de compatibilizar. En Sobre héroes y tumbas cada individuo.

... será ese ser dual y desgraciado que se mueve y vive entre la tierra de los animales y el cielo de sus dioses, que habrá perdido el paraíso terrenal de su inocencia y no habrá ganado el paraíso celeste de su redención ${ }^{12}$.

Idénticas expresiones canalizan un razonamiento similar en Abaddón el exterminador:

Ambigua y angustiada el alma sufre (cómo podría no sufrir!), dominada por las pasiones del cuerpo mortal y aspirando a la eternidad del espíritu, vacilando perpetuamente entre la podredumbre y la inmortalidad, entre lo diabólico y lo divino ${ }^{13}$.

En esta dialéctica de contrarios, lo que en principio era atractivo deviene luego repugnante y viceversa, y las sucesivas elevaciones y rebajamientos de seres e ideas sumen al lector en un angustiante relativismo que es en definitiva el de Sábato. La deformación y la ironía, por otra parte, se aúnan produciendo efectos desconcertantes, y así la verdad es frecuentemente proferida por labios de locos, mendigos, analfabetos o niños.

Otro efecto de la carnavalización y el realismo grotesco en la narrativa es la deformación, transponibilidad, expansión o contracción extraordinarias del espacio y el tiempo -coordenadas vitales y estéticas que en la poética bajtiniana reciben el nombre de cronotopo-. De este modo, los días «se alargan y se deforman como tenebrosos fantasmas sobre las paredes del tiempo» cuando Martín espera ansiosamente la reaparición de Alejandra; en efecto, penetrar en el reino de Alejandra es, mediante el

\footnotetext{
${ }^{10}$ Sobre héroes, p. 28.

${ }^{11}$ Sobre héroes, p. 136.

${ }^{12}$ Sobre héroes, p. 521.

${ }^{13}$ Abaddón, p. 368.
} 
doble hechizo de la noche de verano y su presencia misteriosa, una superación de los umbrales del cronotopo. "Todo podía suceder en aquella atmósfera que parecía colocada fuera del tiempo y del espacio» ${ }^{14}$.

\section{Dialogismo y polifonía}

La asunción de este bagaje cultural magistralmente analizado por Bajtin intensifica en la narrativa de Sábato, lo hemos visto, una polarización dual de personajes, acciones y elementos narrativos. Sin embargo, el aspecto fundamental de la poética sabatiana, y aquel en que la teoría de Bajtin puede arrojar más luz sobre sus producciones, no es la simple constatación de un funcionamiento dual del universo, sino su representación en la praxis del discurso narrativo.

Estamos, en este punto, ante lo que el crítico ruso ha definido con los nombres de dialogismo y polifonía. Ambos conceptos fueron ya elaborados en su primera publicación, Problèmes de la poétique de Dostoïerski, posteriormente se desarrollan ampliamente en el capítulo «Du discours romanesque» de Esthétique et théorie du roman.

El dialogismo, que es un concepto literario, proviene en último término de una realidad lingüística bien conocida: cuando hablamos no hablamos una sola lengua, sino que nuestras propias palabras se desenvuelven en una radical heteroglosia -diferentes lenguas- y hererophonía -diferentes voces individuales-. Más aún, hablar es «hablarcon» y todo enunciado es simultáneamente pregunta, respuesta, afirmación, etc.

Curiosamente, se plantea Bajtin, la estilística tradicional que con tanto detenimiento analizó la lengua poética no prestó atención al discurso narrativo, y si lo hizo se empeñó estérilmente en encontrar en él los mismos procedimientos estilísticos que en el poema.

Pero la narración presenta frente al monologismo de la voz poética una inevitable destrucción del lenguaje único, voz única del narrador, en favor de un reflejo del plurilingüismo de la sociedad.

Pour le prosateur, l'objet est le point de convergence de voix diverses, au milieu desquelles sa voix aussi doit retentir: c'est pour elle que les autres voix créent un fond indispensable, lors duquel ne sont ni saisissables, ni «résonnantes» les nuances de sa prose littéraire ${ }^{15}$.

No se trata entonces de una virtual desaparición de la «voz propia», la voz que el autor asume como privada en su discurso, pero ésta aparecerá siempre incluida como una palabra más entre otras que se acercan o se distancian gradualmente de ella.

${ }^{14}$ Sobre héroes, p. 130.

${ }^{15}$ Mikhail Bakhtine, Esthétique et théorie du roman (París: Gallimard, 1987), p. 102. Bakhtine es la grafía francesa del nombre del maęstro ruso: la utilizaremos en las notas ya que consultamos una edición en francés. 


\section{A. Diálogo y dialogismo}

La forma más directa y simple de dar cabida a la voz del otro en el discurso narrativo, es, claro está, el diálogo. Y volvemos a nuestro objeto de análisis, la novelística sabatiana, para recordar sin necesidad de ejemplificación lo que en una primera lectura aparece ya evidente: Sobre héroes y tumbas es, prácticamente, una larga conversación entre Bruno Bassán y Martín del Castillo, en la que se insertan nuevos diálogos entre Alejandra y Martín, Martín y Bordenave, Quique y sus amigas de la high class, etc., etc. Más acusado resulta aún el procedimiento en Abaddón el exterminador, donde una conversación entre Beba, Sábato y el Dr. Arrambide se desarrolla a lo largo de catorce páginas y aproximadamente lo mismo ocupa el tierno diálogo entre Carlucho y Nacho.

Ha de entenderse que el diálogo puede presentar en el discurso fórmulas diversas, desde la simple transcripción de parlamentos a la inclusión de las palabras del otro mediante la cursiva, las comillas o el paréntesis; del mismo modo, la construcción pseudo-objetiva supone la irrupción de otras voces en la voz del que narra. Obsérvese en este párrafo la superposición de los procedimientos citados:

«Nunca», se dijo a símismo con amargura y casi en alta voz, mientras el Poroto gritaba hace bien Perón y todo eso oligarca habría que colgarlo todo junto a Plaza Mayo «nunca» y sin embargo lo había elegido a él, pero ¿para qué, Dios mío, para qué? ${ }^{16}$.

Por ello, el monólogo puro -si bien es el constitutivo de la poesía- no existe.en la prosa, y Bajtin prefiere hablar de dialógico o dialogismo antes que del término reductivo «diálogo». Todo relato es inevitablemente dialógico, pues el mismo hecho de narrar las acciones del otro presupone adoptar, consciente o inconscientemente, de manera explícita o implícita, sus palabras:

Il n'est pas possible de représenter le monde idéologique d'autri de manière adéquate sans lui donner sa résonance, sans découvrir ses parolesálui; car celles-ci (confondues avec celles del'auteur) peuvent seules étre véritablement adaptées áune representation de son monde idéologique original ${ }^{17}$.

La palabra extranjera, explica Bajtin, puede cumplir dentro del discurso una función autoritaria o persuasiva. La primera, intocable e incontrastable, cae frecuentemente en el peligro anulador del monologismo. No es, evidentemente, el caso de Sábato, que, con honradez que trasciende lo literario y se convierte en actitud personal, presenta junto a la suya las voces de aquéllos que lo contradicen -recuérdese, por ejemplo, la autodegradación a que el autor somete sus ideas estéticas ante los principios revolucionarios de Marcelo-. Pero para ser persuasiva la palabra del otro debe ser reasumida por el discurso actual, presente.

\footnotetext{
${ }^{16}$ Sobre héroes, p. 115.

${ }^{17}$ Bakhtine, p. 155.
} 
Con ello entramos en otra modalidad dialogística, junto al diálogo puro y la hibridación de voces ya analizadas, que Bajtin llama interrelación dialogizada de lenguajes («l'interrelation dialogisée des langages»). En este último procedimiento el narrador no se limita a abrir hueco a otros discursos en el propio, sino que toma posesión de éstos a través de distintas fórmulas narrativas:

a) la estilización, o utilización en beneficio propio de otro discurso ideológico, tal como Sábato se apropia en Abaddón el exterminador de fragmentos del diario del Che y partes militares o periodísticos de su muerte para reivindicar la pureza revolucionaria y dar consistencia al discurso de personajes tacitumos como Marcelo y Palito;

b) la variación, o apropiación de un discurso anterior para su reformulación en una nueva versión, del mismo modo que el discurso histórico argentino es reeditado en los fragmentos de Sobre héroes y tumbas dedicados al General Lavalle;

c) la parodia, o degradación del discurso del otro con finalidad cómica o satírica, tal como el discurso de Bordenave es parodiado en Sobre héroes y tumbas.

En cualquiera de las posibilidades someramente apuntadas, el arte de Sábato se descubre afirmado en el dialogismo, en el contraste de las voces, sin temor de que en alguna ocasión la irrupción de la palabra-otra llegue a destrozar el desarrollo lógico y lineal del discurso:

Là novena compañía cerraba la marcha del famoso 71 (por qué famoso?). No sé, pero así le decían. Creo que nunca lo habían vencido, en ninguna parte del mundo, comprendes? La novela compañía avanzaba por la calle de la Universidad (de la Universidad?). Pero sí, zonzo, la calle Bolívar... ${ }^{18}$.

No hemos atendido, hasta el momento, a una voz fundamental del discurso narrativo: la del lector. El narratario implícito al que se dirige el narrador de Sobre héroes y tumbas cuando comenta e interpreta las acciones y conversaciones de Martín, Bruno, Alejandra, se vuelve explícito en el «Informe sobre ciegos» de Fernando Vidal Olmos y su constante preocupación por la imagen de sí mismo que se forma el lector de su extravagante relato: «Frecuentemente doy una idea equivocada de mi forma de ser, y es probable que los lectores de este Informe se sorprendan por esta clase de ligerezas» ${ }^{19}$.

La palabra de lector es requerida con más vehemencia en Abaddón el exterminador, sin embargo, hasta procurarse la desaparición de la convención que simula el relato como hecho vivido y no representado. Nos referimos especialmente a los fragmentos en que Sábato -Sabato- comenta el proceso de escritura ante un lector involucrado en la narración: «Releo lo que he escrito y advierto que estoy dando una impresión no del todo ecuánime sobre el encuentro»; «Esta palabra se me ha ocurrido al correr de la máquina y me parece reveladora» ${ }^{20}$.

${ }^{18}$ Sobre héroes, p. 89.

${ }^{19}$ Sobre héroes, p. 336.

${ }^{20}$ Abaddón, p. 271 y 278 respectivamente. 


\section{B. Intertextualidad}

Uno de los postulados más fructíferos de Bajtin es el concepto de intertextualidad ${ }^{21}$. Las voces que configuran el dialogismo novelístico no son sólo la de los diversos actores de la anécdota, sino también la palabra de los diversos géneros literarios y otros textos anteriores, literarios o no.

El recurso más llamativo de la intertextualidad sabatiana es la mise en abîme que reutiliza las obras del mismo Sábato en cada una de sus producciones: así, Castel, protagonista de El túnel, reaparece en Sobre héroes y tumbas como emblema de una aspiración amorosa insatisfecha idéntica a la que tortura a Martín y Alejandra; en Abaddón el exterminador nos encontramos de nuevo a Castel, y también a Martín, Alejandra, Bruno, Fernando, Quique..., y otros protagonistas de Sobre héroes y tumbas. Por otra parte, las novelas de Sábato recogen una y otra vez fragmentos -literalmente transcritos, a veces- de sus ensayos, y viceversa, en un procedimiento que se ha intitulado como enchassement de textos.

Sin embargo, creemos que un nuevo aspecto de su poética resulta más significativo aún: la destrucción de las fronteras entre los diversos géneros discursivos. Bajtin señalaba la facilidad con que el relato de cabida a géneros como la confesión, el diario íntimo, el relato de viaje, la biografía, las cartas. Sábato utiliza todos éstos y añade otros más inusuales: Sobre héroes y tumbas se abre como un informe policial desde la noticia preliminar, transcrita como «fragmento de una crónica policial publicada el 28 de junio de 1955 por La Razón de Buenos Aires» ${ }^{22}$. Ciertamente, pronto nos olvidamos de esta condición policíaca del libro, aunque Sábato la recuerda en alguna ocasión posterior: «Estos son los hechos de aquel día. Tendría que pasar un tiempo para que Martín volviera a considerar aquella entrevista con Bordenave, como después de un crimen se examina con atención un lugar o un objeto al que nadie dio importancia» ${ }^{23}$.

Pero no sólo funciona un intertexto policíaco, sino que muy pronto interfiere en la narración un relato distinto que, repartido en cinco fragmentos y destacado tipográficamente por la cursiva, desarrolla en tono lírico y descriptivo, en presente, algunos episodios de la infancia y adolescencia de Alejandra, paralelamente a la narración que de éstos hace la propia Alejandra a Martín.

Por otro lado, el intertexto histórico aparece más allá de la página ochenta pero llega a constituirse en un relato de importancia casi idéntica a la de la historia principal. En veinte fragmentos también identificados por la cursiva Martín se convierte en narrador omnisciente de los últimos episodios de la vida de Lavalle y la fidelidad póstuma de sus soldados -el dialogismo, por cierto, define también este segundo relato, en el que toman la palabra, alternativamente, Lavalle, Bonifacio Acevedo, Pedernera, Alejandro Danel...-.

\footnotetext{
${ }^{21}$ El término «intertextualidad» proviene sin embargo de Julia Kristeva, entusiasta lectora del maestro ruso.

${ }^{22}$ Sobre héroes, p. 9.

${ }^{23}$ Sobre héroes, p. 153.
} 
Por último, y para no extendernos innecesariamente, nos limitamos a señalar otras posibles voces genéricas en Sobre héroes y tumbas: el costumbrismo porteño de las escenas del bar de Chichín, el intertexto lírico de los poemas que Bruno recitaba a Martín, el componente de literatura social y revolucionaria en los episodios de la revuelta peronista, y, cómo no, el impresionante informe biográfico -¿fantástico?- de Fernando Vidal Olmos.

La enumeración ocupará más espacio si pasamos a analizar Abaddón el exterminador. En el seno de su discurso polivocal se inscriben géneros tan distintos como las «confesiones, diálogos y sueños» que dan nombre a la segunda parte de la novela, las «confidencias» que Sábato hace a Bruno, las cuatro «comunicaciones» de Jorge Ledesma, parodias metafísicas, las cartas de Sábato al «remoto muchacho», la entrevista a Pérez Nassif y el reportaje a Sábato, la exposición pseudoteológica del Doctor Alberto J. Gandulfo, los fragmentos del diario del Che, las crónicas periodísticas y los partes militares referidos a su muerte, las digresiones estéticas de Sábato en tomo al arte novelístico, los pseudopoemas en los que la tipografía del verso distorsiona la presentación convencional del discurso narrativo y los poemas auténticos que recita Nacho o que interrumpen la acumulación de datos históricos en torno a la muerte de Ernesto Guevara, los anuncios y las noticias periodísticas que Nacho guarda y se transcriben en el texto, etc.

Dialogismo e intertextualidad configuran los aspectos fundamentales de lo que Mijail Bajtin llamó novela polifónica. En su concepción literaria todo texto prosístico es dialógico, como ya comentamos, pero son Cervantes y Rabelais en los albores de la Edad Modema y Dostoievski en los de la Contemporánea figuras señeras de esta apertura de la palabra propia a las voces de los otros. Emesto Sábato ha manifestado en sus ensayos y creaciones una total adhesión a esta literatura del diálogo y el intercambio de ideas. La crítica de su obra, sin embargo, no ha reparado aún en las posibilidades que la teoría bajtiniana provee para el análisis de sus novelas. Destacamos la excepción de Cesare Segre, que en su artículo «La lucha por la razón» (Cuadernos Hispanoamericanos, 432, junio 1986) deja apenas apuntada esta posibilidad de lectura.

\section{Poética bajtiniana de Sábato}

La lectura bajtiniana de Sobre héroes y tumbas y Abaddón el exterminador es doblemente legítima en cuanto encuentra firme apoyo en las propias concepciones estéticas y literarias del autor, explícitas en sus ensayos y narraciones.

El concepto de «novela polifónica» es fácilmente relacionable con ese otro de novela total que defiende Sábato con pasión:

Es por esa misma hibridez que la «novela total» cobra tanta importancia en esta época de alienación del hombre... Por eso, a lo largo de mi vida, cada vez más he pensado que la ficción ofrece la real integración del hombre desintegrado, por lo menos en sus 
realizaciones más complejas, donde a la narración de hechos se unen elementos que en otro tiempo estaban reservados a la mitología y la magia... ${ }^{24}$.

En el capítulo IV del ensayo Hombres y engranajes, «Las artes y las letras en la crisis», Sábato destaca, junto a la renovación técnica, otros rasgos que le parecen definitorios de la novela contemporánea y que coinciden prácticamente con la corriente cultural en que Bajtin centraba sus estudios: la sumersión en los reinos de lo oculto, lo onírico, lo imaginario, magistralmente representado por las Memorias del subsuelo de Dostoievski, el alzamiento contra la frialdad racionalista y científica del pensamiento apolíneo occidental.

Uno de los pequeños capítulos de Heterodoxia se denomina precisamente «Sobre la necesidad de libre diálogo»: «Diálogo, sí. Pero no sofístico ni catequístico, en los que siempre sale ganando el autor del libreto. Diálogo libre, herético, mal educado» ${ }^{25}$; en otro capítulo titulado «Pensamiento y novela» se insiste en la relación de la novela con lo nocturno y la superrealidad, y nuevamente el modelo elegido es el arte de Dostoievski.

La razón última de esta preferencia por una novela total, polifónica, abierta al debate y la comprensión, trasciende en ambos intelectuales la finalidad meramente estética. Bajtin y Sábato coinciden en una idéntica repulsa del arte formalista, vacío de preocupaciones ideológicas. Entienden los dos que la vanguardia estética se ha acercado, a veces peligrosamente, a una desequilibrada valoración de la forma en despecho del contenido. Y, en la medida en que se trata de dos categorías inseparables, indiscernibles, la postergación del contenido lleva irrevocablemente a un arte conformista y evasivo.

Por otra parte, tanto Bajtin como Sábato otorgan especial interés a evitar el desequilibrio opuesto, que es aquel en el que incurrieron todos los realismos socialistas y artes propagandísticas. En el extremo opuesto al formalismo, en efecto, la literatura vehículo de ideas se convierte a menudo en pseudociencia. La distinción entre literatura y ciencia se realiza en ambos autores en idénticos términos:

C'est là que réside la différence essentielle entre la forme artistique et la forme cognitive. Cette dernière n'a pas d'auteur-crèateur: je trouve la forme cognitive dans l'objet, je ne me retrouve pas en elle, je n'y trouve pas mon activité de créateur ${ }^{26}$.

Les decía que todo arte es individual, y ésa es la diferencia esencial con el conocimiento científico. En el arte, lo que importa es precisamente ese diagrama personal, único, esa concreta expresión de la individualidad...La ciencia es la realidad vista por un sujeto prescindente. El arte es la realidad vista por un sujeto imprescindente ${ }^{27}$.

\footnotetext{
${ }^{24}$ Ernesto Sábato, Hombres y engranajes. Heterodoxia (Madrid: Alianza, 1988), p. 64.

${ }^{25}$ Hombres y..., p. 143.

${ }^{26}$ Bakhtine, p. 70.

${ }^{27}$ Abaddón, p. 180.
} 
Enunperíodo artístico en que se extiende conéxito la idea de unarte deshumanizado, Sábato y Bajtin inician semejantes cruzadas en favor de la personalización de la literatura. Esta dimensión ética del artista proviene del pensamiento filosófico que Todorov resumen, en el caso de Bajtin, con estas hermosas palabras:

Etre signifie être pour autrui, et, à travers lui, pour soi. L'homme ne possède pas de territoire intérieur souverain, il est entièrement et toujours sur une frontière; en regardant à l'intèrieur de soi, il regarde dans les yeux d'autrui ou à travers les yeux d'autrui ${ }^{28}$.

\section{Conclusión}

No hemos pretendido en esta exposición aportar nuevos elementos para el análisis de las técnicas narrativas sabatianas. Prácticamente todos los procedimientos citados el collage de textos, la imaginería subterránea y pesadillesca en particular- habían sido destacados ya por la crítica como herencias del surrealismo que Sábato conoció en su estancia parisina.

Sin embargo, pensamos que es la poética bajtiniana la que con mayor legitimidad puede dar idea de la complejidad narrativa de Sábato, y, lo que no es menos importante en su caso, de los ideologemas culturales, sociales y filosóficos que motivan el empleo de tal práctica narrativa. 